\title{
Dilemma in the Brazilian Tropical Medicine: 'Is speed more important than direction?'
}

\author{
MARCUS V.G. LACERDA ${ }^{1,2,3}$, FERNANDO F.A. VAL ${ }^{2}$ AND WUELTON M. MONTEIRO ${ }^{2,3}$ \\ ${ }^{1}$ Instituto Leônidas \& Maria Deane, Fiocruz, Rua Terezina, 476, 69057-070 Manaus, AM, Brazil \\ ${ }^{2}$ Fundação de Medicina Tropical Dr Heitor Vieira Dourado, Av. Pedro Teixeira, 25, 69040-000 Manaus, AM, Brazil \\ ${ }^{3}$ Universidade do Estado do Amazonas, Av. Carvalho Leal, 1777, 69065-001 Manaus, AM, Brazil \\ Manuscript received on February 5, 2019; accepted for publication on April 15, 2019
}

\begin{abstract}
How to cite: LACERDA MVG, VAL FFA AND MONTEIRO WM. 2019. Dilemma in the Brazilian Tropical Medicine: 'Is speed more important than direction?'. An Acad Bras Cienc 91: e20190132. DOI 10.1590/00013765201920190132.
\end{abstract}

\begin{abstract}
With the recent changes in the epidemiology of infectious diseases in Brazil, research funding has been changing in a manner that does not properly consider biodiversity and poverty-related diseases. The burden of disease and the affected neglected populations need to be part of the equation in developeding countries with limited funding.
\end{abstract}

Key words: Tropical diseases, Brazil, Science, Politics, Public health.

\section{INTRODUCTION}

Art has traditionally guided the way we see science and its achievements, e.g., it is not wrong to say that science fiction movies make science a more popular subject and shape our hopes for the future (Barriga et al. 2010). The Brazilian poet Edson Marques (1962) once declared that 'Change, but start slowly, because the direction is more important than the speed'. Maybe the philosophy behind this quote applies, to some extent, to how Brazilian Science needs to consider its imminent future.

The field of health sciences has been a major driving force in Brazilian research since the glorious times of Oswaldo Cruz, Carlos Chagas, Adolfo Lutz and Emílio Ribas. However, the country's current scenario poses a major dilemma. Funding is limited and research is not a top priority for policy

Correspondence to: Marcus Vinícius Guimarães de Lacerda

E-mail: marcuslacerda.br@gmail.com

ORCID: https://orcid.org/0000-0003-4690-4841 makers. Therefore, priorities need to be determined. Should we prioritize existing diseases or emerging diseases? Should we designate public resources to the health care of neglected populations or to the entire population? In a country where most of its territory is in the tropical zone, existing diseases are transmitted by vectors that are well adapted to high humidity and temperature, and this makes the decision tougher.

Communicable diseases have been controlled over time in Brazil and we have had more successes than failures (Teixeira et al. 2018). Social determinants of health, however, are usually not taken into account. Socioeconomic inequalities have been reduced in Brazil in the last decade, but there is still much work to be done in regards to addressing local social idiosyncrasies (Rasella et al. 2016). Regardless of a non-centralized system, in which municipalities have the role of executing the actions, and the state and federal governments supervise and provide technical advice, respectively, 
public health decisions made in the federal centralized government still believe that 'one size fits all'. Universities, research institutes and local reference laboratories need to be empowered. It is during a crisis that local competence is truly reinforced. The country's geographical differences have been ignored and national standardized policies are conflicting. The same strategy used for health education regarding dengue, in Copacabana, the most famous beach in Rio de Janeiro, is also used in Manaus, in the Amazon. Furthermore, Brazilian universities and research institutes generally don't work in conjunction with any connection to public or private health care institutions, which makes it difficult to provide feedback on research lines and priorities related to disease burden and the real problems of users of the health care system. That is, research is often not done as a response to major public health problems.

Unpredictable emerging infectious diseases challenge an already unstable health system, which is not robust enough to properly absorb the burden of any explosive outbreaks.

A recent yellow fever outbreak in the Southern region of Brazil indicated that universal vaccination was actually needed, and that shortages of vaccines will always occur if our technological facilities are not scaled-up and modernized (Chen et al. 2019). Currently, in some Brazilian cities, there is an ongoing outbreak of measles, a highly contagious disease which is effectively preventable by vaccination. Economic crisis has resulted in massive human migration waves from countries with deteriorated health care systems into Brazilian territory, finding a non-immune population that has neglected its vaccinal status. This makes some topics difficult to understand by the common reasoning of clinicians and epidemiologists. A complete overview of a topic that was apparently simple and well established today requires analysis of specialists in human culture and behavior and communication sciences.
During the Brazilian Zika virus outbreak, the biggest ever seen worldwide, health professionals had to deal with the unknown, and even then, were able to call the world's attention in regards to the former association of fetal intrauterine infection and microcephaly. Brazilian science was in the international spotlight, and the leadership of national scientists consolidated our multidisciplinary expertise in epidemiological, clinical and biological sciences (Possas 2016). National scientific journals, such as the Memórias do Instituto Oswaldo Cruz, responded equally to the call, fast tracking pivotal publications in the field. A substantial amount of funding was designated to Zika virus research. Unfortunately, as the way Brazilian research funding legislation is currently designed, much of it reached researchers when the outbreak had already passed in most locations. As a consequence, other diseases were deprived of funding.

The emerging risk of a Chikungunya fever outbreak is being highly anticipated in Brazil, and multicentric trials are being designed to better understand chronic complications of this acute infection, also transmitted by Aedes aegypti (Azevedo et al. 2015). However, even addressing specific clinical aspects of Dengue, Zika and Chikungunya, all these viruses are transmitted by a single, urban vector, Aedes aegypti (Zanotto and Leite 2018). Following the logic of strategic research, we believe that the common focus of efforts and funding should be targeted to fighting the mosquito and its elimination.

The recent phenomenon of large cities, an international trend, followed by a catastrophic amount of diseases, is what also needs to be understood. It doesn't matter how fast we are in the biological research, if the social sciences are not tightly linked, chances of real solutions are remote.

After the earthquake in Haiti in 2010, Brazil received a wave of human migrants fleeing from that country, which luckily had no impact in the 
resurgence of cholera or filariasis (Rawlinson et al. 2014). The recent migration of Venezuelans to Brazil, in 2018, via the border of Pacaraima/ Santa Elena, in the Northern Brazilian Amazon, has challenged local health systems. To complicate matters, the increase in malaria in both countries posed additional challenges in terms of drug supply chains.

Regarding access to modern health technologies, their availability and accessibility is not uniform to the vulnerable populations inhabiting remote areas in the Brazilian Amazon. A striking example can be observed in the poor access to snake antivenom in localities far from the capitals. The establishment of antivenomproducing facilities following Good Manufacturing Practices, distribution logistics and the institution of epidemiological surveillance are achievements that have led to self-sufficiency in production, which guarantees free access to the treatment of snakebite victims in Brazil. However, late medical assistance and antivenom underdosage is often observed in riverine and indigenous populations, likely explaining the higher lethality and disability rates when compared to urban-living individuals (Fan and Monteiro 2018).

In a country where $99 \%$ of cases of malaria are concentrated in the Amazon alone, caused mostly by Plasmodium vivax, a species with lower fatality rates as compared to the African species Plasmodium falciparum, but leads to cognitive impairment in children and many other economic losses, a vicious cycle of social underdevelopment is the rule (Vitor-Silva et al. 2009). After more than three decades, only recently has a new drug to be used as a single dose for radical cure of this parasite, tafenoquine (Llanos-Cuentas et al. 2014), been approved by the United States Food and Drug Administration, opening venues for possible elimination in the near future.

Therefore, it is time for Brazil to lead research in Global Health in Latin America. Travel
Medicine and Borders Surveillance need not only the release of guidelines, efficient legislation, or the presence of the Armed Forces or non-governmental organizations, but good research, in order to understand social determinants and generate evidence-based policies.

Non-communicable diseases (NCDs) have become a major health priority in Brazil (72\% of all deaths were attributable to NCDs in 2007). Morbidity and mortality due to NCDs are greatest also in the poorer part of the population. Reductions have been primarily in cardiovascular and chronic respiratory diseases, but the prevalence of diabetes and hypertension, together with that of excess weigh, is rising (Schmidt et al. 2011). The role of Brazilian researchers as protagonists in this area is still modest, especially in developing clinical research. Moreover, another difficulty that researchers working with infectious diseases in developing countries face is the lower competitiveness compared to NCD researchers, due to the lower budget allocated to their investigation lines and even the lower impact of journals that publish the results of their research. The effect of these discrepancies on training young talent in the field of neglected diseases can be disastrous.

The process of doing research is hardly under the control of one or two institutions. Usually it has to be a codeshare agreement between those involved in continuous and sustainable funding, international collaboration, personnel training and regulatory agencies (health system, ethics, intellectual property, sanitary control agencies). In Brazil, one does not see these various levels interacting, which generates confusion in advice to the young researcher, and impairs timely responses in public health. This flawed decision making is illustrated by the recent political quid pro quo approval by the former Brazilian president of phosphoetanolamine as a 'cancer pill', without a single clinical trial showing efficacy and safety and against all the current national drug regulatory 
legislation in the country (Kuchenbecker and Mota 2017).

The lack of a national integrated plan for research in the long term, scarce funding, and obsolete research institutions deeply impact what is desired in a country like Brazil. Being proudly part of the group of developing economies together with Russia, India, China and South Africa (BRICS), we not only need to accelerate, but before changing, to see in which direction we want to go.

\section{ACKNOWLEDGMENTS}

MVGL and WMM are research fellows from Conselho Nacional de Desenvolvimento Científico e Tecnológico (CNPq).

\section{AUTHOR CONTRIBUTIONS}

MVGL, FFAV and WMM wrote the manuscript. All authors critically revised the manuscript and approved the final version.

\section{REFERENCES}

AZEVEDO RSS, OLIVEIRA CS AND VASCONCELOS PFC. 2015. Chikungunya risk for Brazil. Rev Saude Publica 49: 1-6.

BARRIGA CA, SHAPIRO MA AND FERNANDEZ ML. 2010. Science Information in Fictional Movies: Effects of Context and Gender. Sci Commun 32: 3-24.

CHEN LH, KOZARSKY PE AND VISSER LG. 2019. What's Old Is New Again: The Re-emergence of Yellow Fever in
Brazil and Vaccine Shortages. Clin Infect Dis 68: 17611762.

FAN HW AND MONTEIRO WM. 2018. History and perspectives on how to ensure antivenom accessibility in the most remote areas in Brazil. Toxicon 151: 15-23.

KUCHENBECKER RS AND MOTA DM. 2017. Miracle drug: Brazil approves never-tested cancer medicine. J Oncol Pharm Pract 23: 399-400.

LLANOS-CUENTAS A ET AL. 2014. Tafenoquine plus chloroquine for the treatment and relapse prevention of Plasmodium vivax malaria (DETECTIVE): A multicentre, double-blind, randomised, phase $2 \mathrm{~b}$ dose-selection study. Lancet 383: 1049-1058.

POSSAS C. 2016. Zika: what we do and do not know based on the experiences of Brazil. Epidemiol Health 38: e2016023.

RASELLA D ET AL. 2016. Assessing the relevance of indicators in tracking social determinants and progress toward equitable population health in Brazil. Glob Health Action 9: 29042.

RAWLINSON T ET AL. 2014. From Haiti to the Amazon: Public Health Issues Related to the Recent Immigration of Haitians to Brazil (PJ Lammie, Ed.). PLoS Negl Trop Dis 8: e2685.

SCHMIDT MI, DUNCAN BB, SILVA GA, MENEZES AM, MONTEIRO CA, BARRETO SM, CHOR D AND MENEZES PR. 2011. Chronic non-communicable diseases in Brazil: burden and current challenges. Lancet 377: 1949-1961.

TEIXEIRA MG, COSTA MCN, PAIXÃO ES, CARMO EH, BARRETO FR AND PENNA GO. 2018. The achievements of the SUS in tackling the communicable diseases. Cienc e Saude Coletiva 23: 1819-1828.

VITOR-SILVA S, REYES-LECCA RC, PINHEIRO TR AND LACERDA MV. 2009. Malaria is associated with poor school performance in an endemic area of the Brazilian Amazon. Malar J 8: 230.

ZANOTTO PMA AND LEITE LCC. 2018. The Challenges Imposed by Dengue, Zika, and Chikungunya to Brazil. Front Immunol 9: 1964. 